\title{
Sou homem e pai sim! (Re)construindo a identidade masculina a partir da participação no parto
}

\author{
Andrea Stopiglia Guedes Braide, ${ }^{1}$ Aline Veras Brilhante, ${ }^{2}$ Cristiani Nobre \\ de Arruda, ${ }^{2}$ Francisco Antonio da Cruz Mendonça, ${ }^{3}$ Jose Manuel Peixoto \\ Caldas, ${ }^{4}$ Marilyn Kay Nations, ${ }^{5}$ Kátia Castelo Branco Machado Diógenes ${ }^{6}$ \\ e Rosendo Freitas De Amorin ${ }^{2}$
}

Como citar Braide ASG, Brilhante AV, Arruda CN, Mendonça FAC, Caldas JMP, Nations MK, et al. Sou homem e pai sim! (Re)construindo a identidade masculina a partir da participação no parto. Rev Panam Salud Publica. 2018;42:e190. https:/ / doi.org/10.26633/RPSP.2018.190

RESUMO Objetivo. Compreender como as experiências de participação ativa do homem no pré-natal e no parto influenciam a ressignificação das identidades masculinas.

Métodos. Estudo de abordagem qualitativa, com análise antropológica interpretativa e suporte etnográfico para descrição densa. Foram incluídos no estudo nove homens que estiveram em um hospital de referência em parto humanizado e participaram do parto de seus filhos no período de abril de 2015 a novembro de 2016. Os dados foram coletados por meio de entrevistas semiestruturadas, de cunho etnográfico, com roteiro flexível elaborado de acordo com as seguintes temáticas: participação ativa no processo do parto, sensações de acompanhar a mãe da criança desde a gestação e significado de ser pai após participar do parto. Os participantes discorreram sobre os tópicos de forma espontânea. As narrativas foram transcritas e analisadas na forma de categorias e interpretação semântica contextualizada.

Resultados. Foram realizados, em média, oito encontros com cada participante. A análise das entrevistas revelou duas categorias temáticas: ressignificação das masculinidades e promoção do autocuidado. As falas caracterizaram o impacto da compreensão de que a masculinidade não se perde se houver uma participação do homem no parto e cuidado dos filhos. Além disso, mostraram que a experiência de participar do parto abriu uma possibilidade de aproximação do homem aos sistemas de saúde para a manutenção do bem-estar, ao invés de necessariamente para o tratamento da doença.

Conclusão. Os homens revelaram que podem ser conscientes do autocuidado e empoderados na condução de sua família, garantindo a construção de uma nova identidade masculina na sociedade contemporânea.

Palavras-chave Pai; identidade de gênero; construção social da identidade; saúde do homem.

Universidade do Porto, Instituto de Saúde Pública do Porto (ISPUP), Porto, Portugal. Correspondência: andreasgbraide@gmail.com

2 Universidade de Fortaleza, Programa de PósGraduação em Saúde Coletiva, Fortaleza (CE), Brasil.

\footnotetext{
3 Centro Universitário Estácio do Ceará, Departamento de Enfermagem, Fortaleza (CE), Brasil.

4 Universidade do Porto, Faculdade de Medicina da Universidade do Porto, Porto, Portugal.
}
Universidade de Harvard, Departamento de Saúde Global e Medicina Social, Cambridge (MA), Estados Unidos.
Universidade de Fortaleza, Departamento de Fisioterapia, Fortaleza (CE), Brasil.


São vários os modelos de masculinidade construídos pela inserção do homem na estrutura social, política, econômica e cultural $(1,2)$. Em cada contexto, entretanto, desponta um modelo de "masculinidade hegemônica", que estabelece atributos, valores e condutas específicas $(1,3)$.

No Brasil, por exemplo, a construção da masculinidade predominante não estimula os homens para o cuidado de si ou do outro $(4,5)$. Esse modelo cultural coloca homens e mulheres em situação de vulnerabilidade sob diferentes perspectivas (6): seja pela vacância nas unidades de atenção primária à saúde (APS) (5), seja pela busca tardia de serviços de saúde, já em estado avançado de adoecimento (7), o fato é que as políticas públicas voltadas para homens esbarram em questões culturais na implementação (8). Nesse contexto, reflexões sobre as diferentes masculinidades mostram que a paternidade também é uma construção influenciada pelas mudanças sóciohistóricas dos papéis de gênero e por novos arranjos familiares (9).

A Política Nacional de Atenção Integral à Saúde do Homem (PNAISH) explicita a relevância da paternidade na promoção da saúde sexual e reprodutiva do homem (10). Nessa linha, a Rede Cegonha, uma estratégia de qualificação da atenção à saúde obstétrica e infantil, valoriza a presença paterna no parto para a humanização do cuidado. Esse tipo de arranjo cria possibilidades para imaginar e exercer direitos e cuidados, inclusive no que diz respeito a sexualidade e paternidade, influenciando a construção da imagética masculina, contribuindo, assim, para reduzir a vulnerabilidades de homens e mulheres $(11,12)$.

Apesar desses avanços, as propostas em geral carecem de aprofundamento nas questões de gênero. Embora os modelos de paternidade sejam tão diversos quanto os de masculinidades (13), as políticas tendem a ignorar seus múltiplos arranjos e possibilidades, sendo permeadas por estereótipos. Na Rede Cegonha, a contextualização do pai como instrumento para a promoção da saúde do binômio mãe-bebê (9) reforça a construção ideológica de que os filhos - desde sua concepção até seu cuidado - são demandas femininas, sendo o homem desobrigado da responsabilidade, uma vez que seu papel seria secundário e complementar (14).
Diante de evidências na literatura que mostram uma ligação entre a ausência dos homens nos serviços e questões de gênero $(9,13,14)$, e partindo do pressuposto de que essas questões de gênero são construções sociais, emerge a necessidade de suscitar momentos e espaços que possibilitem a ressignificação das identidades masculinas. A paternidade é um momento propício para envolver o homem com a possibilidade do prazer em relação à gravidez, ao parto e a relacionamentos mais equitativos no cotidiano doméstico (9).

Nessa perspectiva, em 2015, iniciouse na região Nordeste um estudo com foco no vínculo pai-bebê, com objetivo de compreender, a partir de uma vivência etnográfica, a reorganização da figura paterna e a percepção do pai sobre sua vida no contexto social após o nascimento dos filhos (15). Os resultados aqui apresentados são parte desse amplo estudo etnográfico desenvolvido na região metropolitana de Fortaleza, estado do Ceará, Brasil. O objetivo do presente artigo foi compreender como as experiências de participação ativa do homem no pré-natal e no parto influenciam a ressignificação das identidades masculinas.

\section{MATERIAIS E MÉTODOS}

Esta pesquisa de abordagem qualitativa $(16,17)$, baseada nos pressupostos da antropologia e embasada em recursos etnográficos (18), adotou, como lente teórica, os estudos de gênero e seus desdobramentos nos estudos das masculinidades $(6,7,17)$. O cenário da pesquisa foi um hospital secundário de Fortaleza, referência em assistência à saúde materno-infantil, localizado na Secretaria Executiva Regional VI (SER VI). Implantado na referida maternidade em 2009, o programa institucional "Parto que te quero perto" (18) fez valer a Lei Federal 11 108/2005 (19), que assegura à mulher o direito a um acompanhante durante o parto, beneficiando a inserção paterna no nascimento do bebê e promovendo a sensibilização do homem para assistir ao nascimento do filho e assumir tarefas antes exclusivas dos profissionais de saúde, como cortar o cordão umbilical e colocar na criança a pulseirinha de identificação. Isso pôs em foco o papel do homem na hora do parto e trouxe mudanças sociais importantes, que romperam paradigmas na cultura hospitalar. O "Parto que te quero perto" faz parte do projeto "Encontro dos pais", que acontece sempre na última semana do mês, marcado pela troca de experiências com outros homens e debates com profissionais. Mais que questões técnicas, esses momentos buscam ressaltar a experiência de ser pai. A escolha do local seguiu, portanto, duas motivações principais: primeiro, o pioneirismo do hospital na assistência ao parto humanizado com participação do pai desde o pré-natal e o parto; e, segundo, sua localização na SER VI, apontada pelo Censo Demográfico, em 2016, como a mais violenta da capital Fortaleza. Essa unidade hospitalar recebe parturientes vindas de outras localidades; porém, o estudo ficou restrito aos residentes locais e às características socioculturais específicas. A delimitação captou uma visão relevante para a pesquisa, que pretendia descortinar as entrelinhas de momentos vividos pelo pai: o olhar do homem inserido num contexto que mistura ansiedade, violência e esperança em território de grande periculosidade.

O primeiro passo da coleta de dados foi a aproximação com o campo. De abril de 2015 a novembro de 2016, foram adotadas estratégias específicas: observação não participante, observação participante e diário de campo. Essa fase permitiu aos pesquisadores compreender o local como um território (16), favorecendo a imersão no campo e a reflexividade $(16,17)$. Nessa etapa, houve a aproximação com 46 homens que participavam do Encontro com os pais ou que frequentavam consultas ou espaço obstétrico na sala de parto. O convite para a etapa subsequente aconteceu em seguida a este momento na unidade hospitalar e foi direcionado a $21(45,6 \%)$ participantes ativos no processo do parto, que se mostraram, naquele momento, interessados em participar do estudo e atendiam os critérios de participação. Foram considerados critérios de inclusão: gênero masculino, idade $\geq 18$ anos e residir na Regional VI, Região Metropolitana de Fortaleza. Foram excluídos aqueles que não moravam na regional citada ou não participaram do parto ativamente. A aproximação dos participantes nas visitas domiciliares foi realizada por quatro pesquisadores, e o acompanhamento domiciliar foi realizado por dois responsáveis.

Operacionalizou-se a segunda etapa da coleta de dados por meio de entrevistas semiestruturadas, de cunho etnográfico, 
com roteiro flexível elaborado de acordo com as seguintes temáticas: participação ativa no processo do parto, sensações de acompanhar a mãe da criança desde a gestação e significado de ser pai após participar do parto. Os participantes discorreram sobre os tópicos de forma espontânea, mas chegaram a uma descrição densa $(17,18)$. As entrevistas foram realizadas de maio de 2015 a dezembro de 2016, nas residências dos participantes. Dos 21 possíveis participantes, 14 (66,6\%) permitiram entrada em suas casas e cotidianos. Desses, cinco deixaram de residir na SER VI, restando nove $(64,2 \%)$ participantes.

Após a entrevista inicial, outros contatos foram feitos com cada participante, somando até oito encontros. Foram realizadas anotações em diários de campo e registro das narrativas, sempre com gravador, somando mais de 85 horas de gravações contextualizadas e organizadas dos participantes. As entrevistas gravadas eram transcritas pelo autor responsável após escutar e categorizar falas. Nessa etapa, as perguntas foram construídas de modo a identificar as mudanças fomentadas nesses homens pela experiência recente de participação ativa no pré-natal e no parto e a ressignificação das identidades masculinas.

O número reduzido de informantes foi compensado pela coleta de dados por múltiplas fontes, incluindo diferentes momentos de entrevistas, de modo a permitir uma descrição densa (17) das experiências analisadas. Um número maior de encontros também permitiu a validação dos dados colhidos anteriormente pelos próprios participantes, contribuindo para a confiabilidade das informações.

A análise e a interpretação de dados aconteceram a partir da geração e identificação de categorias com análise temática do conteúdo (20). As transcrições foram tratadas com interpretação semântica contextualizada, por meio de signos, significados e ações (21) refletidos na forma de agir e perceber o papel de pai após aproximação direta do homem no processo de parto, com mudanças até de comportamento e participação no núcleo familiar. $\mathrm{O}$ estudo foi aprovado por comitê de ética em pesquisa e todos os participantes assinaram um termo de consentimento livre e esclarecido, sendo garantidos o anonimato e a confidencialidade dos dados.

\section{RESULTADOS}

A análise das entrevistas revelou duas categorias temáticas: ressignificação das masculinidades e promoção do autocuidado.

\section{Ressignificação das masculinidades}

A participação ativa do homem no parto e pós-parto contribui para o fortalecimento do vínculo pai-filho e para o significado cultural do ser pai. O processo de vinculação permite um novo olhar. Como ideia central para explorar essa categoria, a experiência vivida no pré-natal e nascimento trouxe a possibilidade da ressignificação da masculinidade do ser pai, transcendendo crenças sociais. Essa experiência está ligada a vivências que exploraram a paternidade como questão de saúde em face dos papéis de gênero contemporâneos. O pai pode, de fato, dizer o que sente:

acho que as forças se trocam nessa hora. Ela botava força e eu tremia. (Nildo)

O homem pai, como participante do processo do parto, percebe e contribui ativamente, sem comprometer sua masculinidade, "se preparando junto com a mulher" (Neto). Ainda, é possível quebrar paradigmas para criar uma nova forma de viver o que sente:

no trabalho zoam quando levo mulher no médico, filha pro balé, arrumo casa. (Ton)

A experiência ressignificou o que muitos desses homens imaginavam sobre ser pai:

ser pai tem que ser um pouco de tudo. (Neto)

Essas falas se aproximam de conceitos teóricos que defendem um cuidado dos filhos compartilhado entre mãe e pai e podem estimular uma realidade de transformação da identidade masculina de forma saudável:

\section{Meu filho nasceu, minha vida mudou.} (Ton)

A mudança na percepção do que é ser pai contribuiu para mudar a compreensão de como é ser homem participativo sem confrontar o ser masculino; há aqui uma prerrogativa para mudar a percepção de virilidade e ressignificar a masculinidade do pai que afirma:

\section{Sou homem pro que der e vier! (Fran)}

Vivenciar essa experiência estimulou a percepção da participação ativa desse homem na unidade familiar, saindo da função de suporte da mãe. Esse homem é retirado da margem, da posição de suporte do binômio mãe-bebê, para tornar-se parte de uma tríade e reconhecer que:

\section{ser homem de verdade é fazer de tudo um pouco e ser bom pai. (Tales)}

Desde a observação participante, já era percebido um compromisso com esse novo olhar de ser pai. A preparação se reflete no momento da assistência ao parto e na sensibilização para assistir ao nascimento do filho. O homem dorme ao lado da cama da companheira e do berço do filho, podendo acordar com o choro do bebê e levá-lo para ser amamentado. Esses pais são, de fato, incluídos no processo de nascimento. Como diz um deles:

\section{Participar desde o começo faz se sentir pai de verdade! (Gomes)}

Os resultados demonstram como os modos de construção da identidade paterna contribuem para a ressignificação do papel social masculino. A masculinidade hegemônica - atrelada a força e virilidade - passa a ser desconstruída com a percepção de que ser pai não é apenas fecundar a mãe:

\section{percebi que não é só a relação sexual e a gravidez. (Gomes)}

Ao participar dos encontros, “...aprendi a me cuidá como homem", diz Tales. Muitas ideias podem ser distorcidas até serem vivenciadas, como afirma Leo: "aprendi coisas que nunca imaginei nas reuniões: higiene, massagem, exercício e respiração".

Esse processo de desconstrução e reconstrução identitária é perpassado pela ressignificação histórica e culturalmente construída da imagética da paternidade. Leo percebe que a construção hegemônica ainda é a tradicional, mas seu processo de reconstrução o fez ver além dos estereótipos:

A gente se ajuda, sou homem de verdade, mas não deixo de ser pai! (Leo) 
Aqui a realidade expõe a dualidade dos discursos sociais em relação aos papéis exercidos:

Hoje o pai pode trabalhar fora ou cuidar de casa. (Fran)

Exercer o papel masculino diante da paternidade é uma atribuição do cuidado e, mesmo sem que se perceba, quebra a prerrogativa de que cuidar é dever da mãe quando ela está em casa. Exercer o papel paterno representa muito além do que é exercido fisicamente, pode trazer percepções e reorganização de papéis na família:

Quando tô com minhas filhas brinco, conto estória, brinco, banho e dô jantar. (Nildo)

Essa ressignificação do ser pai culmina na ressignificação do ser homem. Para muitos, ainda é um processo estranho, mas se percebe uma relativa tranquilidade nessas novas descobertas. Para Eudes, "tudo é estranho hoje em dia", como afirma antes de ilustrar as mudanças geracionais: "meu pai dizia que homem trabalha pra mantê a família e mãe cuida dos filhos".

A realidade de Eudes, contudo, diverge daquela de seu pai. Embora o modelo hegemônico de paternidade ainda veja o homem como mantenedor da família, as mudanças dos últimos tempos culminaram em mudanças na estrutura familiar. Desse modo, Eudes continua seu relato:

hoje tô desempregado. Ajudo em casa, cuido do nosso filho e não preciso de ninguém pra ajudar. (Eudes)

Essa percepção é corroborada por Fran, que ressalta o enfraquecimento da linha que separa os papéis do homem e da mulher:

Antigamente era diferente, hoje cada um faz um pouco de tudo. É nossa casa e nossos filhos. Dividimos tudo sem ter coisa de home ou de mulhé. (Fran)

\section{Promoção do autocuidado}

A paternidade pôde, também, aproximar os homens de uma nova possibilidade em relação ao autocuidado, já que permitiu a entrada desses homens no espaço hospitalar sem que estivessem doentes.

Na primeira reunião perguntaram se conhecia prevenção e DST, disse que sim, me senti extraterrestre. Todos riam com vergonha de falar sobre saúde do casal. (Tales)

Pra uma gravidez saudável eu tenho que ser saudável. (Gomes)

A inserção dos homens no sistema de saúde somada à condição de ser pai, que vem ocorrendo de forma instrumental, modifica o binômio mãe-bebê. A participação do pai desde o pré-natal traz um novo olhar para questionamentos e dúvidas esclarecidas nas reuniões sobre assuntos relacionados à vida do casal e a curiosidades sobre o parto:

Aprendemos tudo que acontece quando a mulher tá grávida. Fica fácil de entendê o corpo dela mudando". (Nildo)

Mas existe, ainda, um despertar:

Cuidar da saúde. Conheci os serviços que ajudam na saúde do homem e só ouvia falar. (Tales)

Os homens se aproximam mais como sujeitos que buscam cuidado e direito de saúde, resguardando-se em relação às questões do corpo e da sexualidade. Abrem possibilidades para novos arranjos familiares que chegam a desafiar crenças sobre família, papéis de pai e mãe - o que pode ter impacto no próprio cuidado. As descobertas começam sem que se espere:

...interessante chegar no posto sem doença. Homens também tem que se cuidar. (Leo)

As novas atitudes e ações estimuladas pela paternidade trazem, a partir deste estudo, um novo olhar deste homem sobre programas de ação e promoção de saúde.

Se cuidar como homem é uma forma de cuidar da família. (Neto)

A ativação do autocuidado pode acontecer na participação das reuniões de pré-natal:
Nunca imaginava que tinha prevenção pro homem. (Ton)

Com a aproximação ao serviço de saúde que acompanha a mulher, o homem também pôde ser despertado e estimulado para a importância de cuidar de si mesmo. Sua invulnerabilidade masculina pôde ser ressignificada a partir de um novo olhar sobre autocuidado. Estigmas sociais que o afastam da prevenção e dos cuidados para saúde do homem podem ser trabalhados, com excelentes resultados:

...Eu não me cuidei e nem pedi ajuda. Se a gente não tivesse feito o pré-natal e os exames ia ser pior. (Leo)

\section{DISCUSSÃO}

Os resultados descortinam um panorama de novas possibilidades para a percepção do homem dentro do sistema de saúde e do processo do nascimento. A abordagem teve foco no homem, que pôde ressignificar tanto sua percepção sobre a paternidade como seu papel enquanto gênero masculino a partir da experiência da participação no parto $(2,6,22)$. Esse homem - que é pai - e que pode exercer seu papel sem culpas de uma característica cultural imposta para o gênero masculino, pode ser muito mais do que representação do poder, daquele que provê, e de quem a sociedade exige, impiedosamente, atitudes patriarcais $(4,9,23)$.

Como quaisquer aspectos identitários, a paternidade é uma construção social perene, com influência de aspectos subjetivos e socioculturais (9). Não foi à toa que as experiências de Eudes culminaram na construção de uma imagética da paternidade diversa daquela de seu pai. É em função das necessidades e dos valores dominantes de uma sociedade que se determinam os papéis respectivos de pai, mãe e filho $(24,25)$. A imagética tradicional da paternidade reforça dois pontos do modelo de masculinidade hegemônico. Se, por um lado, a paternidade reafirma a virilidade do homem, por outro é a capacidade de sustentá-los e mantê-los que consolida a força moral masculina (9). A maior inserção feminina no mercado de trabalho e o aumento das responsabilidades maternas nos dois últimos séculos reduziu, progressivamente, o papel paterno de provedor (26). 
Portanto, sem ter sua identidade cultural relacionada ao cuidado, e tendo perdido o papel de provedor, o homem viu sua imagem de pai ser progressivamente eclipsada (26). Nesse cenário, a participação do homem durante a gestação e o parto fomenta a reflexão sobre o exercício da paternidade, favorecendo a consolidação de relacionamentos mais democráticos na esfera doméstica $(26,27)$. Como relatou Leo, essa nova construção permite a coexistência de uma vivência mais afetiva entre a paternidade e o ideal do que é "ser homem de verdade".

Essa nova imagética foi possível devido à ressignificação da própria masculinidade, percebida nas falas. Assim, vale lembrar que nossos informantes residem em uma região do país marcada pelo estigma, violência e influência machista $(23,26)$. Na construção das identidades masculinas, essa influência se destaca, arraigada ao ideário de masculinidade, do "cabra macho" (23).

Contudo, a experimentação e a vivência do nascimento do filho, não como expectador, mas como participante direto, propiciou a esses homens um novo olhar para os significados atribuídos a paternidade e masculinidade (9). O modelo de masculinidade pode ser diferente daquele que era imposto, solitário, reservado e superficial ao longo da vida (2). O homem poderá ser mais sensível e não comprometer sua razão corporal de ser homem ou pai na busca da virilidade $(2,6,22,23,28)$. As ideias iniciais para justificar a participação do pai no momento do parto aliam-se à percepção da nova paternidade, que constitui um momento de transição e crescimento emocional (10, 12-14).

A ressignificação da masculinidade evidenciada na pesquisa foi acompanhada de um movimento de olhar para si mesmo, mudando a relação desse homem com a própria saúde. Culturalmente, o modelo hegemônico de masculinidade leva os homens tanto a sublimarem questões relativas ao autocuidado como a se tornarem mais vulneráveis a eventos de risco de morte precoce por agravos evitáveis (11). Nesse contexto, a ressignificação da masculinidade dos informantes foi acompanhada pela quebra do mito da invulnerabilidade masculina. No Brasil, esse mito é legitimado (1) pelo silenciamento em relação aos cuidados em saúde do homem no âmbito do Sistema Único de Saúde (SUS), sobretudo na atenção primária (29).

É importante reconhecer que a PNAISH $(8,10)$ fez emergir novas possibilidades para inserção do homem no espaço de saúde pública, apesar de seu discurso ainda silencioso quanto à subjetividade do masculino, que sequer levanta questões sobre saúde mental e sexualidade $(5,22)$. Observa-se algo semelhante na Rede Cegonha - resguardadas as particularidades relativas aos papéis sociais de gênero $(30,31)$. Se, por um lado, a PNAISH amplia a apreensão da realidade masculina e o acesso dos homens aos serviços de saúde, por outro, abre espaço para sua problematização a partir de discussões sobre pluralidades de masculinidades no país e de como essas masculinidades influenciam a relação dos homens com os serviços de saúde. Os discursos das políticas não são inertes às práticas historicamente atuantes nas performatividades de gênero (32). A percepção das novas identidades masculinas está diretamente ligada ao contexto local onde o homem está inserido e exige a desorganização do modelo cultural $(10,12,14,33)$.

A presente experiência envolveu o homem desde o parto para viver a paternidade, e foi possível perceber que "o homem é um animal amarrado a teias de significados que ele mesmo teceu" (17, p. 15). Assim, houve uma nova forma de convidar o homem a vivenciar a percepção de ser homem-pai, compreender a busca pelo autocuidado e ainda ser cuidador da família $(2,12,33-35)$.

Ser um Homem de Verdade - não no modelo hegemônico, mas partindo da ressignificação dos ideais de masculinidade - pode ajudar na busca de si próprio e marcar a história pessoal $(2,6,22,34)$. Uma nova caminhada se aproxima e a passagem por grandes mudanças socioculturais é uma das responsáveis por alterar todos os relacionamentos existenciais entre comunidades, família e outros indivíduos. Esse homem que busca definir melhor seu papel redefine sua identidade, reformula valores e direciona seus afetos em busca de caminhos menos frustrantes $(2,3,36)$.

$\mathrm{O}$ presente estudo apresenta limitações, como a dificuldade para abordar o assunto, em se tratando de uma temática pouco explorada, onde o próprio gênero masculino ainda desconhece direitos e políticas públicas para saúde do homem e pouco conhece sobre prevenção em saúde física e mental. Culturalmente, o homem inserido no contexto saúde como usuário está relacionado fortemente com tabu e estigma de fraqueza e não de opção do cuidado. Os pais moradores da Regional VI representaram um desafio em termos de complexidade cultural. Contudo, apesar de estarem inseridos em região de periculosidade da capital, esses homens quebraram paradigmas culturais com sua inserção no parto e puderam mudar perspectivas de comportamento, o que pode culminar com uma mudança inclusive cultural, saindo da visão do machista agressivo ao pai cuidador.

\section{CONCLUSÃO}

Diante da atual crise das masculinidades e do conflito identitário a ela relacionado, os resultados descortinam uma possibilidade para a ressignificação da identidade masculina a partir da reconstrução do ideário da paternidade. Esse processo, contudo, demanda um foco no homem - não como suporte para a mãe, mas como pai.

Desse modo, o estudo evidencia a participação do pai no momento do nascimento do filho sob a ótica dessa reconstrução identitária. A participação apenas coadjuvante do pai traz o risco de reforçar o estereótipo hierárquico que coloca homens e mulheres em situação de vulnerabilidade.

Agradecimentos. Os autores agradecem especialmente as contribuições de todos participantes deste estudo. Este artigo é um produto do Projeto The Father Baby Bonding financiado pela Fundação Melinda \& Bill Gates com a colaboração do Grupo de Pesquisa (CNPq) - Cuidados e Humanização em Saúde em Pessoas Fragilizadas, sob a coordenação de Marilyn Nations.

Conflitos de interesse. Nada declarado pelos autores.

Declaração. As opiniões expressas no manuscrito são de responsabilidade exclusiva dos autores e não refletem necessariamente a opinião ou política da RPSP/PAJPH ou da Organização PanAmericana da Saúde (OPAS). 


\section{REFERÊNCIAS}

1. Scott JW. Gender: a useful category of historical analysis. Am Hist Rev. 1986;91(5): 1053-75.

2. Nader MB, Caminoti JM. Gênero e poder: a construção da masculinidade e o exercício do poder masculino na esfera doméstica. Anais do $16^{\circ}$ Encontro Regional de História da ANPUH-RIO: Saberes e Práticas Científicas. 28 de julho a $1^{\circ}$ de agosto de 2014, Rio de Janeiro, Brasil. ANPUH-Rio: Rio de Janeiro; 2014. Disponível em: http:/ / www.encontro2014.rj.anpuh.org/ resources / anais / 28/1400262820_ ARQUIVO_Generoepoderaconstrucaoda masculinidadeeoexerciciodopodermascu linonaesferadomestica.pdf Acessado em outubro de 2018.

3. Hankivsky O. Women's health, men's health, and gender and health: implications of intersectionality. Soc Sci Med. 2012; 74(11):1712-20.

4. Ribeiro CR, Gomes R, Moreira MC. Encontros e desencontros entre a saúde do homem, a promoção da paternidade participativa e a saúde sexual e reprodutiva na atenção básica. Physis. 2017;27(1):41-60.

5. Gomes R, Moreira MCN, Nascimento EF, Rebello LEFS, Couto MT, Schraiber LB. Os homens não vêm! Ausência e/ou invisibilidade masculina na atenção primária. Cienc Saude Colet. 2011;16 Suppl 1:S983-92.

6. Gomes R, Albernaz L, Ribeiro CRS, Moreira MCN, Nascimento M. Linhas de cuidados masculinos voltados para a saúde sexual, a reprodução e a paternidade. Cienc Saude Colet. 2016;21(5):1545-52.

7. Couto MT, Gomes R. Homens, saúde e políticas públicas: a equidade de gênero em questão. Cienc Saude Colet. 2012;17(10): 2569-78.

8. Gomes R, Leal AF, Couto MT, Knauth D, Lima AM, Moura EC, et al. Avaliação das ações iniciais da implantação da política nacional de atenção integral à saúde do homem. Rio de Janeiro: IFF; 2012.

9. Ribeiro CR, Gomes R, Moreira MCN. A paternidade e a parentalidade como questões de saúde frente aos rearranjos de gênero. Cienc Saude Colet. 2015;20(11): 3589-98.

10. Brasil. Portaria 1994/2009. Diário Oficial da União; 2009. Disponível em: http://bvsms. saude.gov.br/bvs/saudelegis/gm/2009/ prt1944_27_08_2009.html Acesso em 10 de março de 2018.

11. Moura EC, Gomes R, Falcão MTC, Schwarz E, Neves ACM, Santos W. Desigualdades de gênero na mortalidade por causas externas no Brasil, 2010. Cienc Saude Colet. 2015;20(3):779-88.

12. Carneiro RG, Ribeiro FB. Partos, maternidades e políticas do corpo. Civitas. 2015; 15(2):181-9.
13. Soares RLSF, Christoffel MM, Rodrigues EC, Machado MED, Cunha AL. Ser pai de recém-nascido prematuro na unidade de terapia intensiva neonatal: da parentalidade a paternidade. Esc Anna Nery. 2015; 19(3):409-16.

14. Carrara S, Russo JA, Faro L. A política de atenção à saúde do homem no Brasil: os paradoxos da medicalização do corpo masculino. Physis. 2009;19(3): 659-78.

15. Nations MK, Braide ASG, Arruda CN, Mendonça FAC, Diógenes KCBM Cavalcante RC, et al. Vínculo pai-bebê: promoção da saúde materno-infantil e da não violência na sociedade. 22nd IUHPE World Conference on Health Promotion Promoting Health and Equity. 22 a 26 de maio de 2016. Curitiba, Brasil. Saúde Sociedade: São Paulo; 2016. Pp. 880. Disponível em: http://iuhpeconference 2016.net.br/IUHPE_AbstractBook.pdf Acessado em outubro de 2018

16. Minayo MCS. O desafio do conhecimento: pesquisa qualitativa em saúde. $9^{\mathrm{a}}$ ed. São Paulo: Editora Hucitec; 2006.

17. Geertz C. O Saber Local: novos ensaios em antropologia interpretativa. Petrópolis: Vozes; 2014

18. Rocha AET. Humanização do parto: o homem nordestino no nascimento do filho em um hospital público de Fortaleza-Ceará [dissertação]. Fortaleza (CE): Universidade de Fortaleza; 2010. Disponível em: https:/ / uol.unifor.br/oul/ObraBdtdSiteTrazer.do? method=trazer\&ns $=$ true\&obraCodigo $=$ 86710 Acessado em outubro de 2018.

19. Brasil. Lei 11 108/2005. Disponível em: http:/ /www.planalto.gov.br/ccivil_03/_ Ato2004-2006/2005/Lei / L11108.htm Acessado em outubro de 2018.

20. Bardin L. Análise de conteúdo. Lisboa: Edições 70; 2000.

21. Bibeau G, Corin EE. Beyond textuality: asceticism and violence in anthropological interpretation. Berlin: Mouton de Gruyter; 1995.

22. Louro GL. Gênero, sexualidade e educação: uma perspectiva pós-estruturalista. $16^{a}$ ed. Petrópolis: Vozes; 2001.

23. Brilhante AVM, Silva JG, Vieira LJES, Barros NF, Catrib AMF. Construcción del estereotipo del "macho nordestino" brasileño en las letras de forró. Interface. 2018; 22(64):13-28.

24. Silva Junior PM, Maia MVCM, Ivenicki A. Homens por vir: reflexões sobre o processo de construção das masculinidades na educação infantil a partir de jogos e brincadeiras. Rev Educ em Perspec. 2018;9(1):67-86.

25. Bento B. Masculinidades críticas e a proposição analítica e relacional nas contemporâneas discussões de gênero. Rev Estud Fem. 2015;23(3):1026-9.
26. Couto MT, Dantas SMV. Gênero, masculinidades e saúde em revista: a produção da área na revista. Saude Soc. 2016;25(4): 857-68.

27. Passos E, Campos GWS. A PNH como um modo de fazer: desafios para a humanização do SUS. Diretrizes para reorganização do trabalho em saúde [DVD]. Brasília: Ministério da Saúde; 2009. Disponível em: https: / / www.youtube.com / watch? $\mathrm{v}=4 \mathrm{M} 2 \mathrm{og} 0 \mathrm{Nt}$ 9Ls Acessado em outubro de 2018.

28. Kleinman A. The illness narratives: suffering, healing, and the human condition. Nova Iorque: Basic Books; 1988.

29. Separavich MA, Canesqui AM. Saúde do homem e masculinidades na Política Nacional de Atenção Integral à Saúde do Homem: uma revisão bibliográfica. Saude Soc. 2013;22(2):415-28.

30. Carneiro RG. Dilemas antropológicos de uma agenda de saúde pública: Programa Rede Cegonha, pessoalidade e pluralidade. Interface. 2013;17(44):49-59.

31. Carneiro RG. Cenas de parto e políticas do corpo: uma etnografia de práticas femininas de parto humanizado [tese]. Campinas (SP): Universidade Estadual de Campinas; 2011. Disponível em: http://repositorio.unicamp.br/bitstream/REPOSIP/280585/1/Carneiro_Rosa mariaGiatti_D.pdf Acessado em outubro de 2018.

32. Butler JP. Problemas de gênero: feminismo e subversão da identidade. Tradução de Renato Aguiar. Rio de Janeiro: Civilização Brasileira; 2003.

33. Carvalho MLM. Participação dos pais no nascimento em maternidade pública: dificuldades institucionais e motivações dos casais. Cad Saude Publica. 2003;19(Suppl 2): S983-92.

34. Promundo-Brasil. A situação da paternidade no Brasil. Rio de Janeiro, Brasil: Promundo; 2016. Disponível em: https:/ / promundo.org.br/recursos/situacao-dapaternidade-no-brasil/ Acessado em outubro de 2018.

35. Viana Júnior MM. Masculinidades: ampliando o debate. Rev Forum Identidades. 2017;23:87-108.

36. Bourdieu P. A dominação masculina. Tradução de Maria Helena Kühner. 11 ${ }^{a}$ ed. Rio de Janeiro: Bertrand Brasil; 2012.

Manuscrito recebido em 18 de novembro de 2017 Aceito em versão revisada em 20 de julho de 2018. 
ABSTRACT

Yes, I am a man and a father! (Re)constructing male identity through engagement in childbirth

Keywords Fathers; gender identity; social construction of identity; men's health.
Objective. To study how the male experience of playing an active role in prenatal care and childbirth influences the resignification of male identity.

Method. This is a qualitative study employing interpretive anthropological analysis supported by ethnographic methods to produce a thick description. The study included nine men attending a center of excellence in humanized childbirth and who played an active role in the birth of their child in the period from April 2015 to November 2016. Data were collected through semi-structured, ethnographically-oriented interviews, with a flexible script that explored the following themes: active participation in childbirth, feelings associated with standing by the child's mother since pregnancy, and meaning of fatherhood after participation in childbirth. The participants talked about these topics freely. The narratives were transcribed and analyzed in terms of categories and contextual semantic interpretation.

Results. On average, eight meetings were held with each participant. Analysis of the interviews revealed two theme categories: resignification of masculinity and promotion of self-care. The utterances reflect the participants' understanding that masculinity is not lost if men play an active role in childbirth and care. In addition, they reveal that the experience of participating in childbirth opened a possibility for men to approach the healthcare system to maintain health, rather than to strictly treat disease.

Conclusion. The men participating in this research revealed that they can be aware of self-care and become empowered to lead their families, ensuring the construction of a new male identify in contemporary society.
RESUMEN

¡Sí, soy hombre y padre! (Re)construir la identidad masculina a través de la participación en el parto
Objetivo. Estudiar cómo la experiencia masculina de desempeñar un papel activo en la atención prenatal y el parto influye en la resignificación de la identidad masculina.

Métodos. Estudio cualitativo que empleó el análisis antropológico interpretativo apoyado por métodos etnográficos para producir una descripción densa. El estudio incluyó a nueve hombres que asistieron a un hospital de referencia en partos humanizados y que participaron en el nacimiento de sus hijos entre abril de 2015 y noviembre de 2016. Los datos se recopilaron a través de entrevistas semiestructuradas, orientadas etnográficamente, con un guion flexible que exploró los siguientes temas: participación activa en el parto, sentimientos asociados con el acompañamiento de la madre desde el embarazo y el significado de la paternidad después de la participación en el parto. Los participantes hablaron sobre estos temas de manera espontánea. Las narraciones fueron transcritas y analizadas en términos de categorías e interpretación semántica contextual.

Resultados. En promedio, se realizaron ocho reuniones con cada participante. El análisis de las entrevistas reveló dos categorías temáticas: resignificación de la masculinidad y promoción del autocuidado. Las respuestas reflejaron la comprensión de los participantes de que la masculinidad no se pierde cuando los hombres desempeñan un papel activo en el parto y el cuidado de los hijos. Además, revelaron que la experiencia de participar en el parto abrió la posibilidad de que los hombres se acercaran al sistema de salud de manera preventiva, en lugar de acudir para el tratamiento de una enfermedad.

Conclusión. Los hombres que participaron en esta investigación revelaron que pueden ser conscientes del autocuidado y resultar empoderados en la conducción de sus familias, asegurando la construcción de una nueva identidad masculina en la sociedad contemporánea.

Palabras clave Padre; identidad de género; construcción social de la identidad; salud del hombre. 